\title{
ANALISIS SERAT SULUK SYEKH SITI JENAR
}

\author{
Frenky Icksan Nugraha \\ Program Pascasarjana Universitas Muhammadiyah Malang \\ frenky_nugraha52@ymail.com
}

\begin{abstract}
ABSTRAK: Penelitian ini dilatarbelakangi oleh fakta bahwa dari zaman kuno hingga peradaban baru banyak orang yang masih belum memahami sikap hak beragama, seperti dalam kisah tokoh agama legendaris yang dianggap menyimpang dari norma agama.

Masalah dari penelitian ini adalah "bagaimana ajaran" hamba Manunggaling Gusti "dalam serat pengasingan Sheikh Siti jenar".

Setiap agama, kepercayaan, dan budaya di dunia memiliki konsep dan pemahaman tentang Tuhan. Namun, walaupun Tuhan digambarkan dengan berbagai cara berbeda, hampir semua agama dan kepercayaan di dunia sepakat bahwa Tuhan adalah sumber, pusat, dan tujuan sebenarnya dari seluruh makhluk di alam semesta ini, yang tujuannya adalah mencari satu orang tahu.

Subjek dalam penelitian ini difokuskan pada ajaran mata pelajaran Manunggaling Gusti yang pada waktu itu dicap sebagai ajaran kontroversial, sehingga tujuan saya untuk mengeksplorasi makna di balik serat Syekh Siti adalah sejenis mistisisme.

KATA KUNCI: Gusti, Kawula, Manunggaling, Mengajarkan.
\end{abstract}

\begin{abstract}
These researches background by the fact that from ancient times until the new civilization many of the people who still do not understand the attitude of the religious right, as in the story of a legendary religious figures who are considered to deviate from religious norms.

The problems of these researches is " bagimanakah teachings " Manunggaling Gusti servant " in seclusion fiber Sheikh Siti jenar ".

Every religion, beliefs, and culture in the world has the concept and understanding of God . However, although God is described with a variety of different ways, almost all religions and beliefs in the world agree that God is the source, the center, and the true purpose of the whole being in this universe, the purpose of which is look for one man to know.

Subjects in these researches are focused on the teachings Manunggaling Gusti subjects which at that time labeled as controversial teachings, so my goal to explore the meaning behind the fiber Sheikh Siti jenar mysticism.
\end{abstract}

KEYWORDS: Manunggaling, Teachings, Gusti, Servant.

\section{PENDAHULUAN}

Ketika dihadapkan pada peradaban baru, banyak di antara manusia memilihnya jalan yang dianggap benar, salah satunya jalan wali yang mungkin bisa membawa manusia memasuki peradaban yang penuh dengan kesadaran untuk menuju Tuhan, sebab manusia Jawa menganggap jalan wali adalah jalan menuju kebebasan.

Syekh Siti Jenar adalah seorang tokoh legendaris, misterius, sekaligus kontroversial, yang hidup di tanah jawa pada abad 14- 15 Masehi. Nama lain Syekh Siti Jenar adalah Syekh Lemah Abang, Syekh Siti Abrit dan Siti Rekta.
Syekh Lemah Abang atau yang biasa dikenal dengan nama Syekh Siti Jenar, bergelar Prabu Satmata atau raja yang tampak oleh mata. Konon menurut ceritanya, Syekh Siti Jenar pernah mendapatkan wejangan dari Nabi Khidir, Sunan Kalijaga dan Sunan Bonang (Ki Reksa Bawana, 2007, hal. 35).

Dalam bahasa Jawa "Siti" berarti tanah atau bumi pertiwi, sedangkan "Jenar" artinya merah. Manusia memang diciptakan dari tanah, jadi tubuh manusia tidak lebih dari sekedar tanah merah. Sisanya roh Allah (Ki Reksa Bawana, 2007, hal. 35-36). Dari namanya saja, sudah terkandung tinggi tentang asal usul 
FON : Jurnal Pendidikan Bahasa dan Sastra Indonesia

Volume 14 Nomor 1 Tahun 2019

manusia, tentang dari mana manusia yang fana ini bermula.

Dalam penyebaran agama Islam di pulau Jawa pada saat itu, Syekh Siti Jenar memiliki ajaran berbeda dengan ajaran Wali Sanga (sembilan tokoh penyebar agama Islam di Jawa saat itu). Ia terkenal dengan ajaran Ilmu Kasampurnan dan Manunggaling Kawula Gusti terkenal sebagai kontroversial dan menghebohkan pada masanya. Ajarannya yang berbeda dengan wali lainnya dianggap sebagai Wali Murtad atau Wali sesat (Zazuli, 2011, hal. 9).

Untuk membatasi permasalahan ini, perlu merumuskan masalah sehingga materi yang dibahas bisa terfokus pada Bagaimanakah ajaran-ajaran "Manunggaling Kawula Gusti” dalam Serat Seluk Syekh Siti Jenar?

Adapun tujuan penelitihan yang sederhana ini bertujuan Untuk mengetahui ajaran-ajaran Manunggaling Kawula Gusti dalam serat suluk Syekh Siti Jenar dan mendeskripsikan simpulan dalam ajaran-ajaran Manunggaling Kawula Gusti dalam serat suluk Syekh Siti Jenar yang dianggap kontroversial. Manfaat hasil penelitihan ini diharapkan mampu memberikan sedikit pengetahuan tentang ajaran-ajaran Manunggaling Kawula Gusti dalam serat suluk Syekh Siti Jenar.

\section{METODE}

Sehubungan dengan masalah penelitian ini, maka peneliti mempunyai rencana kerja atau pedoman pelaksanaan penelitian dengan menggunakan Pendekatan kualitatif, dimana yang dikumpulkan berupa pendapat, tanggapan, informasi, konsep-konsep dan keterangan yang berbentuk uraian dala mengungkapkan masalah. Penelitian kualitatif adalah rangkaian kegiatan atau proses penyaringan data atau informasi yang bersifat sewajarnya mengenai suatu masalah dalam kondisi, aspek atau bidang

tertentu

dalam

kehidupan objeknya. (Hadari Nawawi, 1994, hlm. 176)

Jadi yang dimaksud dengan pendekatan kualitatif adalah prosedur penelitian yang menghasilkan penelitian data deskriptif berupa kata-kata tertulis atau lisan tentang orang-orang, perilaku yang dapat diamati sehingga menemukan kebenaran yang dapat diterima oleh akal sehat manusia.

\section{HASIL DAN PEMBAHASAN}

Ajaran Manunggaling Kawula Gusti dalam Serat Suluk Syekh Siti Jenar terbagi oleh dua pokok pembahasan yaitu pandangan hidup Syekh Siti Jenar tentang hakikat manusia dan hakikat kiamat.

\section{Pandangan hidup Syekh Siti Jenar tentang hakikat manusia}

Pandangan hidup Syekh Siti Jenar tentang hakikat manusia atau manusia yang sebenarnya, maka dia juga mengajarkan makna pribadi. Pada manusia, yang menjadi bentuk fokusnya ialah bentuk lahiriahnya. Sedangkan pada pribadi, yang menjadi tekanannya adalah substansi yang ada pada manusia. Keberadaan abstrak manusia. Batin manusia. Ia merupakan wujud yang tidak menyandang pangkat, jabatan, posisi, gelar dan atribut lainnya. Manusia sebagai bentuk senyawa tanah, air, udara dan api akan kembali hancur terurai menjadi unsur-unsurnya. Kata 'pribadi' berasal dari bahasa kawi yang artinya 'sendiri'. Satu diri. Ya, diri sendiri. Itulah pribadi! Karena itu, kepribadian berarti sifat khas dan hakiki seseorang yang membedakan dari diri yang lain. Jadi, pribadi itu unik. Tak ada dua pribadi yang sama persis, boleh jadi sifat-sifat fisiknya yang sama (Chojim, 2002, hal. 104).

Meskipun demikian, manusia juga memiliki hawa nafsu dan sifat kebinatangan yang sering kali membuat masalah, bahkan malapetaka di dunia ini. Dalam diri manusia terdapat sifat-sifat 
FON : Jurnal Pendidikan Bahasa dan Sastra Indonesia

Volume 14 Nomor 1 Tahun 2019

positif dan sifat-sifat negatif yang secara bersamaan dapat tumbuh dan berkembang mengikuti kesadaran dan kehendak manusia tersebut. Berbagai tatanan etika, aturan moral, norma agama, dan hukum negara diciptakan untuk mengatur manusia demi terciptanya suatu kehidupan bermasyarakat yang ideal, damai dan harmonis.

Namun, jika ditinjau lagi secara lebih mendalam, keberadaan manusia di bumi ini memiliki makna dan peran yang lebih dari sekedar itu. Sebenarnya manusia diciptakan di bumi ini untuk bisa membuktikan kebenaran Tuhan karena hanya manusialah yang bisa memikirkan dan memahami-Nya. Manusia ada di bumi ini agar tujuan ilahi di alam semesta ini terungkap.

\section{Pandangan hidup Syekh Siti Jenar dalam hakikat kiamat yang terdapat dalam konsep ajaran manunggaling kawula gusti.}

\author{
Boyan sasar benjang ingsun urip \\ Datan ngawur sapuniko pejah \\ Uripku cangkrameng kene \\ Anemu jisim wujud \\ Balung sungsum otot myang daging \\ Getun kasiksa pejah \\ Panasaran agung \\ Goda rencana blis setan \\ Pira-pira naraka rumaket jisim \\ Belenggu rante modang \\ (Pupuh Dhandhanggula, Serat Suluk \\ Syekh Siti Jenar)
}

Guna mempertajam pemahaman kita tentang serat suluk Syekh Siti Jenar ini, maka saya akan menerjemahkan :

Tujuan kehidupan saya

Jangan sampai tahu setelah mati

Hidupku ku pelajari dari sini

Menemukan jasad yang berwujud

Tulang, sungsum, otot yang terbungkus daging

Menyesal, mati tersiksa
Penasaran terbesar

Tergoda rencana iblis setan

Berapa banyak nerakah yang dekat dengan

tubuh

Terbelenggu rante yang mengikat kuat

(Pupuh Dhandhanggula, Serat Suluk Syekh

Siti Jenar)

Dalam serat ini, Syekh Siti Jenar menjelaskan bahwa "boyan sasar benjang ingsun urip, datan ngawur sapuniko pejah, uripku cangkrameng kene" agar manusia memiliki tujuan kehidupan, jangan sampai tahu setelah mati oleh karna itu Syekh Siti Jenar mengajarkan hidup kepada santri-santri untuk mengenal dirinya sendiri serta mempelajari hidup dari sini. Jangan sampai tersesat dalam kehidupan yang akan datang tidak boleh merawak-rambak karena Syekh Siti Jenar meyakini bahwa hidup dengan jasmani ini seperti berada di alam kematian.

\section{a. Jawaban dari penjelasan tentang syariat yang sudah menjadi palsu atau formalitas belakang. Perhatikan pernyataan Syekh Siti Jenar berikut ini.}

Sadat salat pasa tan pati

Seje jakat kaji mring Mekah

Iku wes palson kabeh

Nora kena ginugu

Sadayeku durjaning Bumi

Ngapusi liyan titah

Sinung swarga besuk

Wong bodho anut aliya

Tur nyatane padha bae durung uning

Seje ingsun lemahbang

Guna mempertajam pemahaman kita tentang serat suluk Syekh Siti Jenar ini, maka saya akan menerjemahkan :

$$
\begin{gathered}
\text { Syahadat, sholat, puasa tiada guna } \\
\text { Beda, zakat dan haji ke Mekah } \\
\text { Itu sudah palsu semua } \\
\text { Tidak bisa dipercaya } \\
\text { Itu semua kedurjanaan di Bumi }
\end{gathered}
$$


FON : Jurnal Pendidikan Bahasa dan Sastra Indonesia

Volume 14 Nomor 1 Tahun 2019

Penipuan sesama manusia

Diberi harapan bakal masuk surga

Orang bodoh mengikuti cara orang lain

Tapi kenyataanya belum tahu yang sebenarnya

Saya Lemah Abang berbeda dengan mereka

Dalam pernyataan ini, Syekh Siti Jenar menyatakan bahwa untuk apa syahadat, sholat dan puasa apabila tidak tahu tujuannya yang sebenarnya serta menerapkan dan mengamalkan ke dalam kehidupan ini. Untuk apa zakat dan haji ke Mekah apabila kita tidak bisa mengontrol diri sendiri, tidak mengetahui dirinya sendiri, karena itu semua kedurjanaan budi dunia, penipuan terhadap sesama manusia yang diberi harapan bakal masuk surga.

\section{b. Pandangan Syekh Siti Jenar tentang kesatuan hamba dengan gusti}

Pemahaman garis besar ajaranajaran "Manunggaling Kawula Gusti" dalam serat suluk Syekh Siti Jenar ini, mengajak seluruh umat Islam pada masa itu, untuk diajarkan serta mengenalkan ilmu tasawuf yang artinya kesucian. Tasawuf adalah sebuah metode dalam ajaran Islam untuk dapat bersatu dengan kemutlakan Tuhan. Untuk bisa bersatu dengan kemutlakan Tuhan ini maka seseorang harus suci batin terlebih dahulu. Berikut ini ajaran manunggaling kawula gusti dalam serat suluk Syekh Siti Jenar.

$$
\begin{aligned}
& \text { Jumenenge kawula lan gusti } \\
& \text { Wus dumunung sira kabeh } \\
& \text { Ing bumi langit pitu, } \\
& \text { Saka ananira pribadi } \\
& \text { Sajroning urip } \\
& \text { Wijange lah rasa kena } \\
& \text { Lile rosul rasanira kang sejati, } \\
& \text { Tunggal rasane sukma } \\
& \text { (serat Syekh Siti Jenar) }
\end{aligned}
$$

Guna mempertajam pemahaman kita tentang serat suluk Syekh Siti Jenar ini, maka saya akan menerjemahkan :

\author{
Berdirinya hamba dan gusti \\ Sudah berada dalam tubuh semua \\ Di bumi langit tujuh \\ Ada dalam pribadi \\ Dalam hidup \\ Petunjuknya lah bisa dirasakan \\ Cahaya rosul menjadi rasa dalam batin \\ sejati \\ Menjadi satu rasa dalam sukma \\ (serat Syekh Siti Jenar)
}

Maka jelaslah kita tentang konsep ajaran manunggaling kawula gusti dalam serat suluk Syekh Siti Jenar, Sebagaimana yang sudah sering dipahami oleh sebagian orang, dalam diri manusia terdapat tiga lapisan utama atau tiga jenis kesadaran, yaitu:

\section{1) Dimensi dan kesadaran fisik}

Ini adalah lapisan dan bagian dari kesadaran manusia yang paling rendah dan terbatas. Dimensi fisik dan kesadaran fisik ini hanya terbatas pada dimensi ruang-waktu yang kita tinggal ini.

\section{2) Dimensi dan kesadaran jiwa}

Ini adalah lapisan dan kesadaran yang bersifat sebagai perantara. Dimensi dan kesadaran ini bersifat lebih halus dari sekedar dimensi dan kesadaran fisik. Meskipun jasmani kita sudah meninggal dan musnah terurai, lapisan tubuh dan kesadaran jiwa ini tidak akan ikut musnah atau mati.

\section{3) Dimensi dan kesadaran roh}

Ini adalah lapisan dan kesadaran manusia yang tertinggi sekaligus yang paling halus dari seorang manusia. Inilah yang menjadi intisari kehidupan yang bersifat kekal dan abadi. Roh adalah percikan sinar Tuhan sehingga roh pun memiliki sifat-sifat yang berasal dari Tuhan. Roh adalah sinar Tuhan yang bersemayam dalam diri manusia. Roh jugalah yang menjadi sarana perhubungan 
FON : Jurnal Pendidikan Bahasa dan Sastra Indonesia

Volume 14 Nomor 1 Tahun 2019

antara kita dan Tuhan. Roh inilah yang menjadi diri sejati setiap insan.

\section{KESIMPULAN}

Pokok keilmuan Syekh Siti Jenar disebut sebagai "Ngelmu Ma'rifat Kasampurnaning Ngurip” (ilmu ma'rifat kesempurnaan hidup). Ranggawarsita menyebutkan basis ilmiah ajaran tersebut aplikasinya adalah metafisika dan etika.

Ajaran Syekh Siti Jenar merumuskan tentang the Reality of the Absolute being (hakikat Dzat Yang Maha Suci) yang memiliki sifat, nama dan perbuatan "Kami". Dari "Kami" inilah kemudian muncul "ada" dan "keadaan" lain, yang sifat hakikinya adalah "Tunggal".

Manusia yang dalam hidupnya di alam kematian dunia ini disebut sebagai khalifatullah (wakil Allah atau pecahan ketunggalan Allah), dan kemudian ia harus berwadah dalam bentuk jisim (jasmani) ia harus menyandang gelar "kawula", sebab jasad harus melakukan aktivitas untuk memelihara jasadnya dari kerusakan dan untuk menunda kematian yang disebut :"ngibadah" kepada yang menyediakan raga (Gusti). Maka kawula hanya memiliki satu tempat kembali, yakni Allah, sebagai asalnya. Maka manusia tidak boleh terjebak dalam wadah yang hanya berfungsi sementara sebagai "wadah" Roh Ilahi. Justru Roh Ilahi inilah yang harus dijaga guna menuju ketunggalan kembali (Manunggaling Kawula Gusti).

Dari simpulan di atas, ada beberapa hal yang disarankan penulis kepada pembaca dan peneliti lain yang berminat sebagai berikut.

1. Dalam pengajaran sastra disarankan sebagai salah satu media apresiasi, guna mempertajam apresiasi mahasiswa khususnya di bidang penelitian sastra. Pemahaman tentang ajaran-ajaran manunggaling kawula gusti dalam serat suluk Syekh Siti
Jenar yang dianggap kontroversial oleh masyarakat yang ada di pulau Jawa.

2. Hasil penelitian bahwa ajaran Manunggaling Kawula Gusti yang di teliti penulis memiliki keutamaan bagaimana sikap dan cara beragama yang benar.

3. Penulis menyarankan bagi pembaca dan pendengar kisah Syekh Siti Jenar, agar kita semakin memahami tentang cara bersikap dalam beragama sehingga keharmonisan dalam masyarakat Indonesia ini, tetap terjaga baik persatuan dan kesatuan.

\section{DAFTAR PUSTAKA}

Atmosuwito, Subijantoro. (2010). Perihal sastra \& religiusitas dalam sastra. Bandung: Sinar Baru Algensido.

AW, Yudhi. (2012). Serat Dewaruci Pokok Ajaran Tasawuf Jawa. Yogyakarta: PT Buku Seru.

Bawana, Ki Reksa. (2007). Ketika Tuhan Bersatu Diri. Yogyakarta: Narasi.

Chodjim, Achmad. (2013). Syekh Siti Jenar: Makrifat Kasunyata 1. Jakarta: PT Serambi ilmu semesta.

Fathurahman, Oman. (1999). Menyoal Wahdatul Wujud. Bandung: Penerbit Mizan.

Moelong, Lexy J. (2011). Metode penelitian kualitatif. Bandung: PT remaja rosdakarya.

Simuh. (1988). Mistik Islam kejawen Raden Ngabehi Ranggawarsita: suatu studi terhadap serat Wirid Hidayat Jati. Universitas Michigan: Penerbit Universitas Indonesia.

Zazuli, Mohammad. (2011). Syekh Siti Jenar. Jakarta: PT Serambi Ilmu Emesta.

Zoetmulder, P.J. (1991). Manunggaling Kawula Gusti Pantheisme dan monism dalam sastra suluk jawa. Jakarta: PT Gramedia Pustaka Utama. 
FON : Jurnal Pendidikan Bahasa dan Sastra Indonesia

Volume 14 Nomor 1 Tahun 2019

Derani, Saidun. (2014). Syekh Siti Jenar : Utomo, Agus Himmawan. (2016). Tauhid

Pemikiran dan Ajarannya. Al-

Turās Vol. XX, No. 2 (325-347).
Al-Wujud Syeikh Siti Jenar Dan

Unio Mystica Bima. Jurnal Filsafat Vol. 40, Nomor 2 (116127). 